\title{
PREVALENCE OF CHILDHOOD SKIN DISORDERS ATTENDING AT OUTPATIENT PEDIATRIC HOSPITAL
}

\author{
NANDINI THUMMANAPALLY ${ }^{1}$, KAVITHA LAWDYAVATH $^{1}{ }^{1}$ CHARANDAS GURUVA $^{1}$, DEEPTHI ENUMULA ${ }^{1 *}$ \\ SASTRY PVK ${ }^{2}$, SHYAM SUNDER ANCHURI ${ }^{1}$
}

${ }^{1}$ Department of Pharmacy Practice, Balaji Institute of Pharmaceutical Sciences, Warangal, Telangana, India. ${ }^{2}$ Department of Pediatric P.V.K Sastry Children's Clinic, MGM Hospital, Kakatiya Medical College, Warangal, Telangana, India. Email: deepthi.e9@gmail.com

Received: 03 September 2019, Revised and Accepted: 19 March 2020

ABSTRACT

Objective: The objective of the study was to study the prevalence of various skin diseases in pediatric population.

Methods: A prospective observational study was conducted at private children's outpatient clinic in Warangal from March to August 2018 with the prior approval from the Institutional Ethical Committee BIPS/IEC/2018/P8. A total of 200 patients with various skin diseases of age group <17 years were included in the study.

Results: Out of 200 pediatric skin disorders, male children 138 (69\%) outnumbered female children 62 (31\%). The mean age of the study population was found to be $5.85 \pm 4.11$ years. About $64 \%$ of the patients are from rural area and $36 \%$ are from urban. The percentage of skin disorders is allergic infections (26\%), bacterial infections (23\%), viral infections (11\%), fungal infections (7.5\%), parasitic infections (6\%), autoimmune disorders (4\%), and skin adnexa $(2.5 \%)$.

Conclusion: Our study concludes that the prevalence of allergic and bacterial skin infections was found to be common among male children from rural area.

Keywords: Skin disorders, Pediatrics, Prevalence, Eczema, Impetigo, Chickenpox, Tinea corporis.

(C) 2020 The Authors. Published by Innovare Academic Sciences Pvt Ltd. This is an open access article under the CC BY license (http://creativecommons. org/licenses/by/4. 0/) DOI: http://dx.doi.org/10.22159/ajpcr.2020.v13i5.35578

\section{INTRODUCTION}

Skin development is a non-stop process. In pediatrics skin, all the anatomical structures are present, but they are immature when compared to the skin of adults [1]. However, infants have smaller corneocytes and thinner stratum corneum which lasts until 2 years of age. When compared with adults, skin of newborns contains fewer fibrils and decreased dermal collagen, thereby making it more prone to skin diseases [2]. In India, skin diseases are becoming increasingly important due to many factors such as varied climate, genetic, age, overcrowding, nutrition habits, poor hygiene, and pollution [3]. Pediatric dermatology deals with the diagnosis, treatment, and prevention of skin diseases occurring in childhood $[4,5]$. Special skills are required while dealing with children's having skin diseases as they differ in clinical presentation, treatment, and prognosis [6]. Children being the major part of the population are often neglected, especially neonates having skin problems are not taken seriously by the community [7]. Skin diseases in rural areas are more prevalent due to their poverty and lack of awareness among the people [8]. Skin infection can be defined as the invasion and multiplication of microorganism such as bacteria, fungal, viral, or parasites on the skin [9]. The previous studies from other parts of the country had reported the pattern of skin diseases, there appears to be a recent shift from higher frequency of skin infections and infestations to appearance of eczemas as leading cause of skin morbidity [10-12]. There have been few studies done on the prevalence of skin disorders from India. Our present study attempts to provide a better understanding of various skin disorders in children with figures.

\section{METHODS}

\section{Study design and settings}

A prospective observational study was conducted from March to August 2018 at private children hospital by taking informed consent directly from patients and patient representatives who attended the clinic regarding their skin complication with the prior approval from the Institutional Ethical Committee BIPS/IEC/2018/P8.

\section{Study size}

In our study, 200 pediatric patients with skin disorders were enrolled and noted.

\section{Study criteria}

Inclusion criteria

Pediatric population with skin disease of age $<17$ years who are attending outpatient clinic during the study period were included in the study.

Exclusion criteria

1. Patients above 17 years are excluded from the study

2. Children with chronic diseases are excluded from the study

3. Children who having skin manifestation as a part of systemic diseases are excluded from the study.

\section{Materials}

A predesigned pro forma was used for collecting data which include patient demographics such as age, gender, locality, duration of illness, type of infection, symptoms, and treatment.

\section{RESULTS}

Out of 200 patients, males were 138 (69\%) and females were 62 (31\%). The mean age of the study population was found to be $5.85 \pm 4.11$ years. Among 200 studied patients, $64 \%$ of patients attended to the outpatient clinic were from rural areas and about $36 \%$ of patients were from urban areas. The children were classified according to the age group: 
Infants ( $0-2$ years), preschool (2-5 years), school age (between 5 and 12 years), and adolescents (12-17 years), as shown in Fig. 1.

Types of skin infections observed in our study were allergic infections, bacterial infections, viral infections, fungal infections, arthropod infections, unknown cause infections, genodermal, sweat glands, autoimmune infections, nutritional, mutation of the SLC39A4 gene, in born error metabolism, photo allergy, physiological, and friction blister, as shown in Table 1.

\section{Bacterial infections}

Among 200 cases, the prevalence of bacterial infections $(n=46)$ wasimpetigo 19 (41.3\%), folliculitis 10 (21.7\%), furuncle 7 (15.2\%), pyoderma 4(8.6\%), hordeolum externum 3 (6.5\%), ecthyma 2 (4.3\%), and facial cellulitis $1(2 \%)$, the examples of bacterial skin infections are shown in Figs. 2 and 3.

Table 1: Types of skin infections observed in children

\begin{tabular}{ll}
\hline Types of skin infections & Number of patients (\%) (n=200) \\
\hline Allergy & $52(26)$ \\
Bacterial & $46(23)$ \\
Viral & $22(11)$ \\
Fungal & $15(7.5)$ \\
Arthropod & $12(6)$ \\
Unknown & $11(5.5)$ \\
Genodermal & $10(5)$ \\
Sweat glands & $1(0.5)$ \\
Pilosebaceous glands & $3(1.5)$ \\
Eccrine sweat glands & $5(2.5)$ \\
Autoimmune & $8(4)$ \\
Nutritional & $8(4)$ \\
Mutation of the SLC39A4 gene & $2(1)$ \\
IEM & $2(1)$ \\
Photo allergy & $1(0.5)$ \\
Physiological & $1(0.5)$ \\
Friction blister & $1(0.5)$ \\
\hline
\end{tabular}

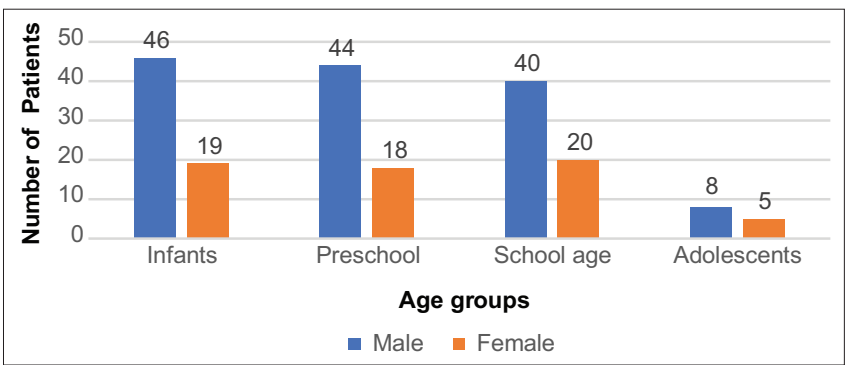

Fig. 1: Age group distribution among pediatrics

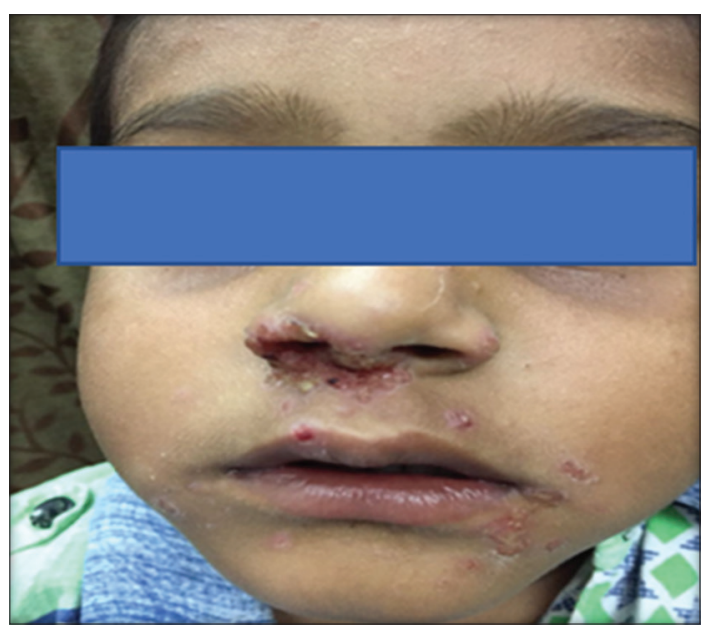

Fig. 2: Impetigo
Allergic infections

In allergic infections $(n=52)$, the prevalence of eczema was $28(53.8 \%)$ followed by papular urticaria 21 ( $40.38 \%)$, prurigo simplex $2(3.84 \%)$, friction blister $1(1.92 \%)$, the examples of allergic infections were represented in Figs. 4-7.

\section{Autoimmune disorders}

In autoimmune disorders $(n=8)$, the prevalence of alopecia were $3(37.5 \%)$ followed by psoriasis 2 (25\%), Vitiligo 1 (12.5\%), Down syndrome 1 (12.5\%), Systematic lupus erythematous 1 (12.5\%), some of the examples of auto-immune disorders were represented in Figs. 8 and 9.

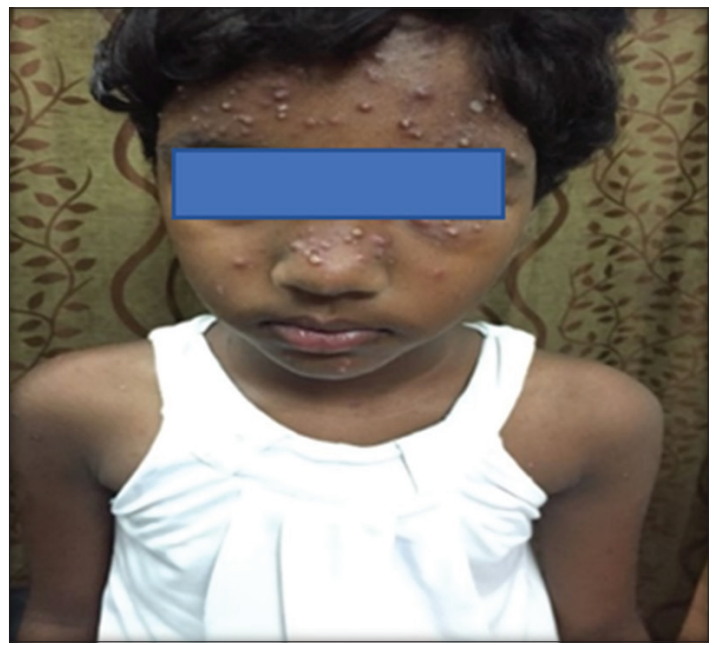

Fig. 3: Folliculitis

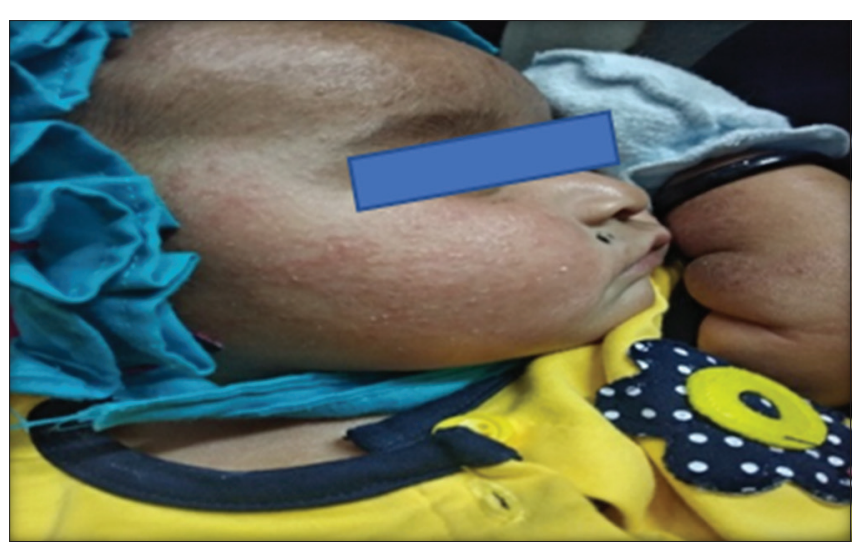

Fig. 4: Atopic dermatitis

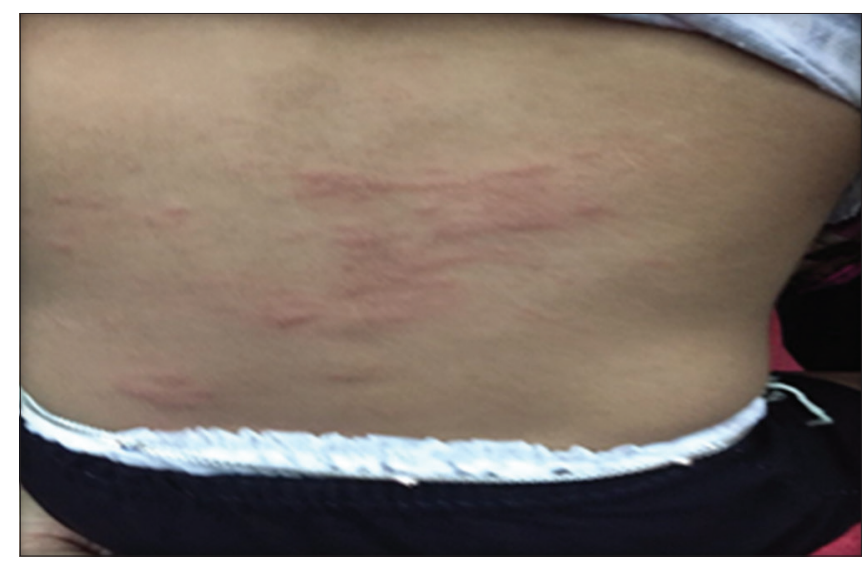

Fig. 5: Urticaria 


\section{Skin adnexa}

Among 9 skin adnexa cases, the prevalence of Miliaria rubra were $5(55.5 \%$ ) followed by acne vulgaris $3(33.3 \%)$, pompholyx $1(11.1 \%)$, an example was shown in Fig. 10.

\section{Fungal infections}

In fungal infections $(\mathrm{n}=15)$, the highest prevalent is tinea corporis $5(34 \%)$, the second highest prevalent is tinea versicolor $5(20 \%)$ and tinea capitis $3(20 \%)$, onychomycosis $2(13 \%)$, and oral candidiasis $2(13 \%)$, the examples of fungal infection are represented in Figs. 11 and 12 .

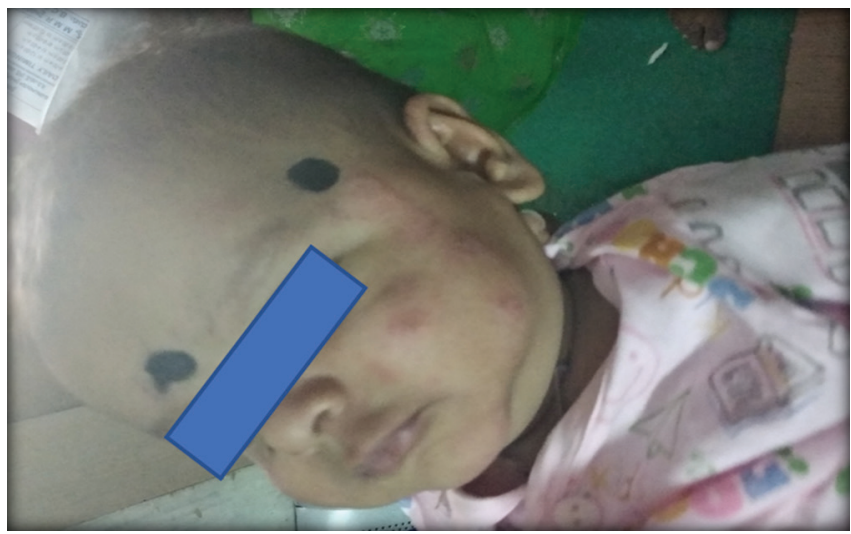

Fig. 6: Seborrheic dermatitis

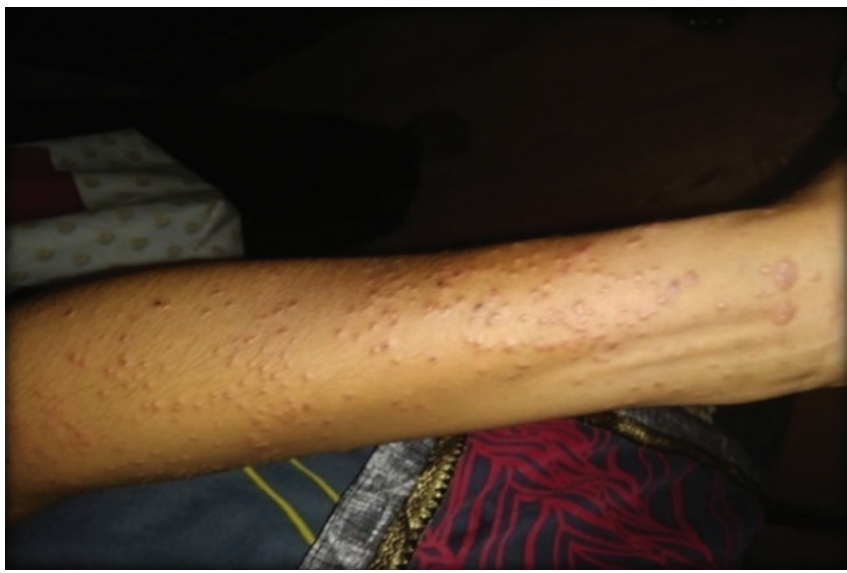

Fig. 7: Contact dermatitis

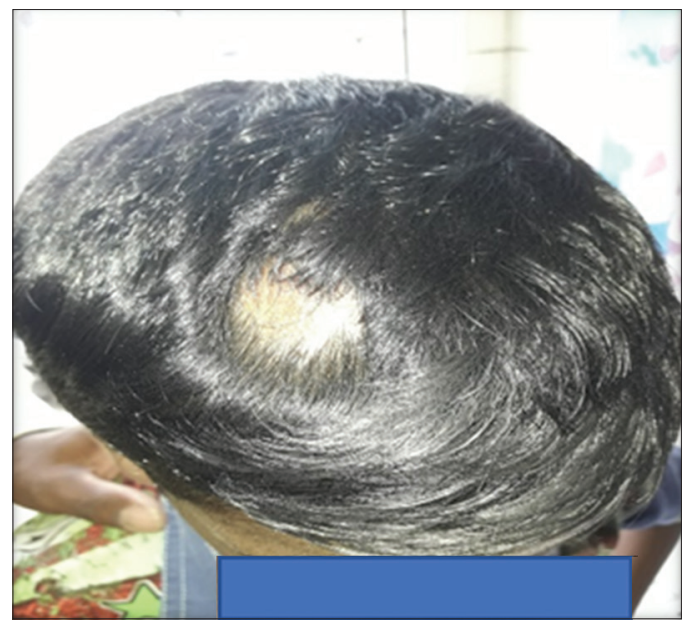

Fig. 8: Alopecia areata
Genodermal diseases

In genodermal diseases $(\mathrm{n}=10)$, the highest prevalent was ichthyosis vulgaris $2(25 \%)$ and neurofibromatosis type $12(25 \%)$, the second highest prevalent is aplasia cutis congenita $1(12.5 \%)$, hemangioma $1(12.5 \%)$, lichen stratus $1(12.5 \%)$, and nevus $1(12.5 \%)$. An example of genodermal infections is shown in Fig. 13

\section{Viral infections}

Among 22 viral infection cases, the highest prevalent viral infection is varicella $14(64 \%)$, the second highest prevalent is viral exanthema $5(23 \%)$, herpes gingivostomatitis $1(5 \%)$, herpes labialis $1(5 \%)$, and herpes simplex $1(5 \%)$. An example of viral infection was shown in Fig. 14.

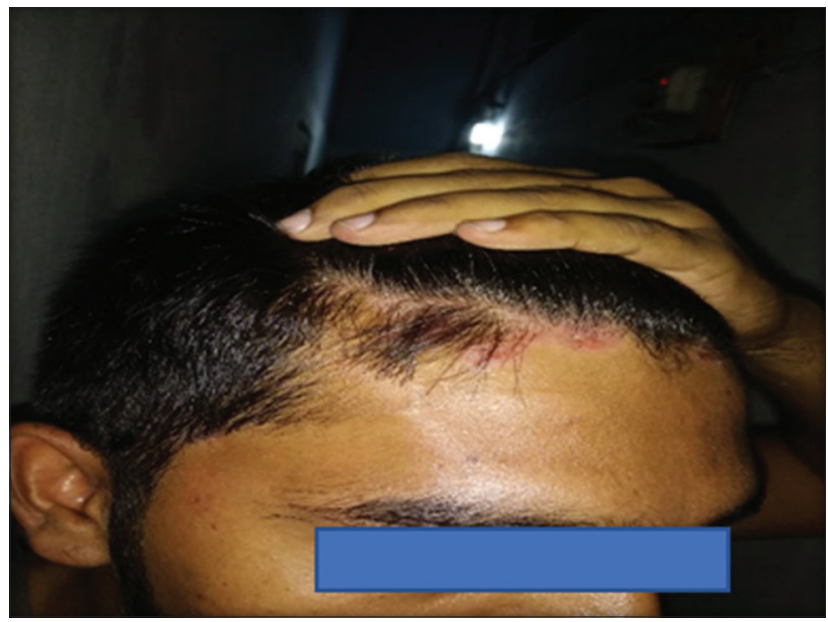

Fig. 9: Scalp psoriasis

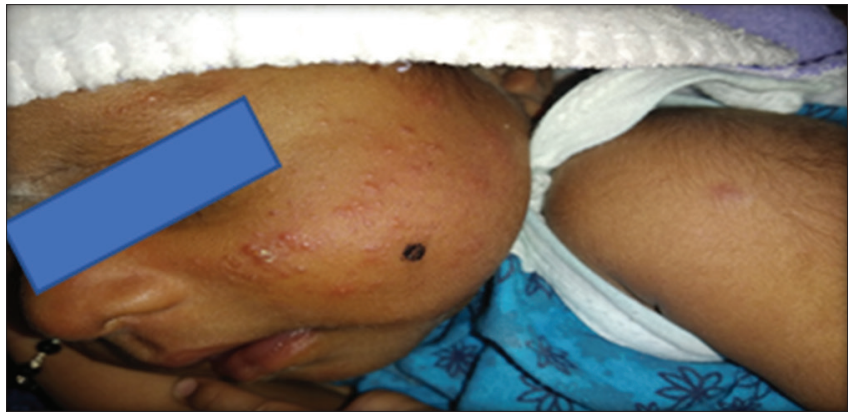

Fig. 10: Acne vulgaris

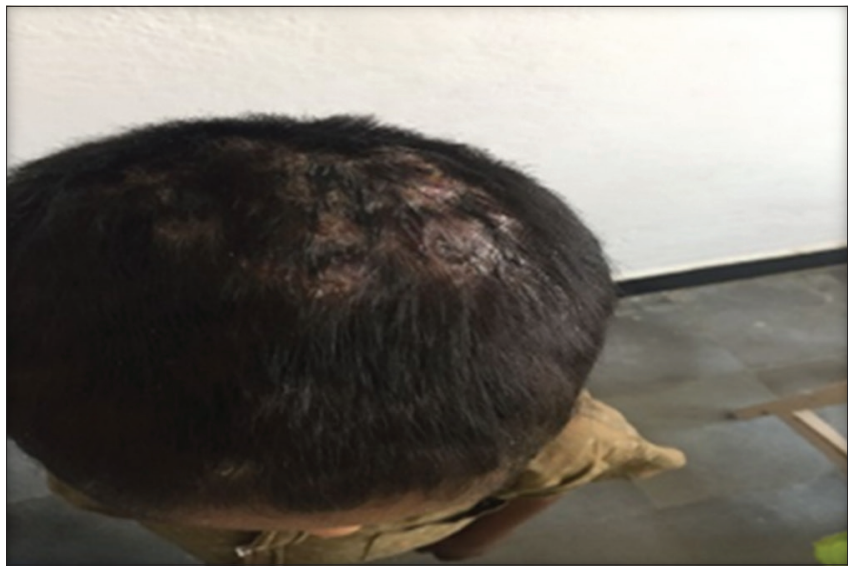

Fig. 11: Tinea capitis 
Nutritional cases

A total of eight nutritional cases among children were found and depicted in Table 2 .

\section{DISCUSSION}

The Epidemiological studies on skin disorders were influenced by many factors such as genetic, geographical area, varied climate, socioeconomic factors, living conditions, and medical resources play a major role. Based on our finding in relation to sex, male predominance was observed. The male-to-female ratio was 22.5:1 which was complying with a study from India conducted by Sardana et al. [13] where male predominance was observed, male-to-female ratio was 1.07:1.

According to age, many cases were observed in children under 14 years of age and lowest number of cases was observed in infantile group. On the other hand, when the results were assessed according to etiology, allergic skin infections (26\%) and bacterial skin infections $(23 \%)$ were most prevalent. In allergic skin infections, eczema (14\%) was the most prevalent among the studied groups. These eczematous skin diseases were in the second position in studies conducted in India (26.95\%) by Sardana et al. [13] and Pakistan 21\% by Yasmeen and Khan [14].

In many parts of the world, dermatitis was in the top list among the studied groups of skin diseases. Frequency of atopic dermatitis was observed high in our study which contributes to $2 \%$ of all cases. It was reported 2.6\% in Egyptian study conducted by Mostafa et al. [15]. In other areas, the frequency of atopic dermatitis was found to be high in the study conducted by Sethuraman and Bhari [16]. Lower incidence of atopic dermatitis and eczema was found in the study conducted by Dadapeer et al. [17]. This imbalance between the two studies can be explained by the difference in industrialization, nutritional habits. The second high-frequency allergic infection in our study is papular urticaria (10.5\%). Studies from India reported $3.59 \%$ conducted by Sardana et al. [13] and 5.27\% conducted by Karthikeyan et al. [18]. In the present study, it was most prevalent in below 8 years of age-old children. The frequency of papular urticaria may be high due to the varied climate and insect bites.

Table 2: Number of nutritional cases in pediatrics

\begin{tabular}{ll}
\hline Types of nutritional cases & Number of patients $(\%)(\mathbf{n}=\mathbf{8})$ \\
\hline Acrodermatitis enteropathy & $2(25)$ \\
Angular cheilitis and glossitis & $2(25)$ \\
Bitot's spot & $2(25)$ \\
Pellagra & $1(12.5)$ \\
Phrynoderma & $1(12.5)$ \\
\hline
\end{tabular}

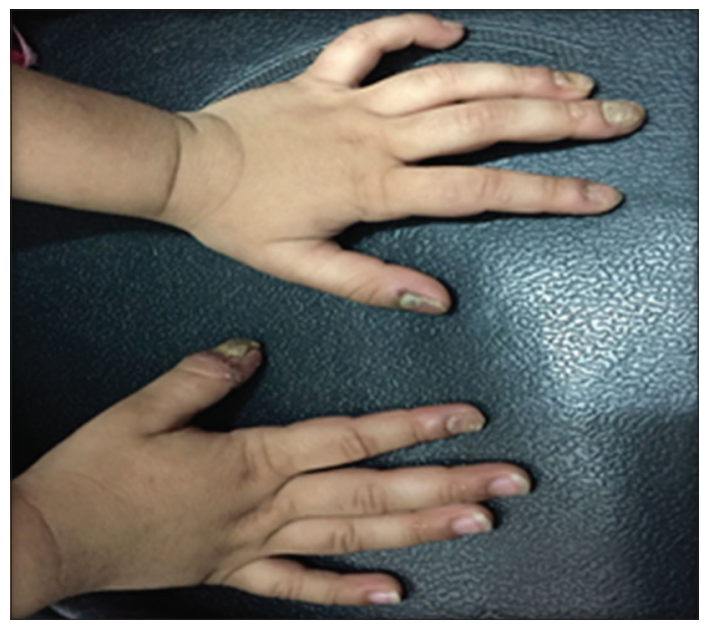

Fig. 12: Tinea unguium
Bacterial skin infection (23.4\%) is the second most frequent and prevalent infectious skin disease. Egyptian study on prevalence of skin diseases among infants and children conducted by Mostafa et al. [15] shows similar results. In bacterial infections, impetigo was the most prevalent representing (9.5\%) of all cases. On the other hand, high frequency of impetigo (49.4\%) observed in a study which was conducted by Yeoh et al. [19]. In our results, the highest frequency of bacterial infection can be due to the hot humid climate, overcrowding, and low socioeconomic factors.

Viral infections represent (11\%) third most frequent skin infection. The prevalence of viral infections was low (9.90\%) in the study conducted in Turkey by Polat et al., [3] and high prevalence (19.7\%) in the study conducted by Kiprono et al. [20] in Switzerland. In viral infections, the most common one was varicella representing $7 \%$ of all cases with viral infections. High frequency of chickenpox $9.15 \%$ by the study conducted by Essmat et al. [21].

Fungal infections (5\%) revealed fourth high frequency in our study. Fungal infections were reported to be high $(15.8 \%)$ in Nigeria study conducted in children by Ogunbiyi et al. [22] and reported high $(18.8 \%)$ in the study conducted by Kelbore et al. [23] in Southern Ethiopia. The reason for such imbalance between various reports may be due to the variation in fungal species prevalence in different areas. Tinea corporis, tinea capitis, and tinea versicolor were in top list among the group of fungal infections. In our study, tinea versicolor is most prevalent, this is compared with the study conducted by Ravindra et al. [24] which showed that tinea versicolor is the most common. On the other hand, next most prevalent fungal infection is tinea capitis. This shows similarity with Iraq studies conducted by Fathi and Al-Samarai [25] and Palestine studies conducted by Ali-Shtayeh et al. [26]. A study in Pakistan [27] reveals that fungal infections were the most common (20.6\%).

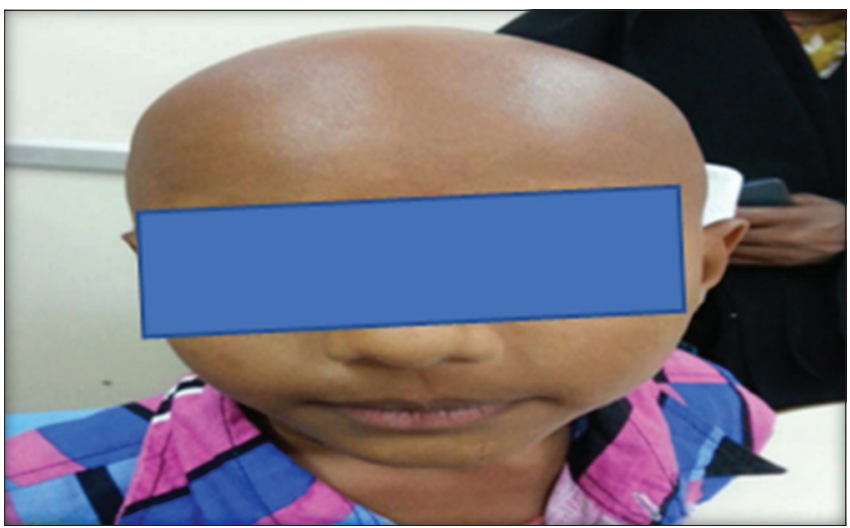

Fig. 13: Aplasia cutis congenita

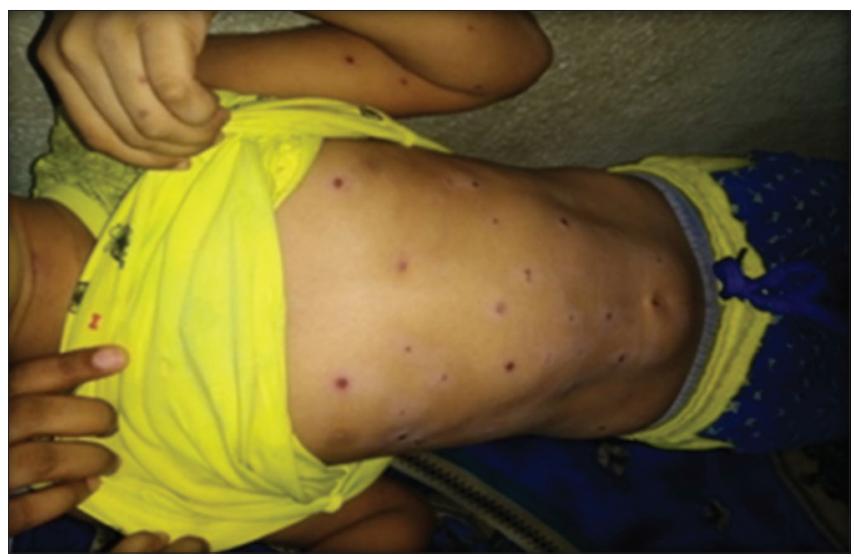

Fig. 14: Varicella/Chicken pox 
Parasitic skin diseases were fifth in frequency in our study 6\%. Among parasitic skin diseases, scabies was found to be more prevalent representing $6 \%$ of all cases. On the other hand, high prevalence rate of scabies $21.7 \%$ was revealed by Javed and Jairamani [28] at Karachi.

In autoimmune skin disorders, alopecia, psoriasis, and vitiligo were found to be most prevalent. In our study, vitiligo was the second most prevalent autoimmune skin disorder, this is compared with the study conducted by Hafi et al. [29].

\section{CONCLUSION}

From our study, we have concluded that allergic skin reactions and bacterial skin infections are more prevalent. In allergic infections (eczema and papular urticaria), bacterial infections (impetigo, folliculitis, and furuncle) in viral skin infections, varicella, and viral exanthema and in autoimmune disorders, alopecia areata and in fungal infections, tinea corporis and in disorders of skin adnexa, acne and in nutritional skin diseases, phrynoderma and in genodermal cases, neurofibromatosis type- 1 and ichthyosis are majorly affected. Based on the results of our study, we have found that male children were majorly affected with skin diseases than females. Most of the children with skin diseases attended to the clinic were from rural areas; therefore, knowledge of the skin diseases, early diagnosis, treatment, and preventive measures for the affected children need to be taken to breakout the skin diseases.

\section{ACKNOWLEDGMENTS}

The authors would like to acknowledge the Department of Pharmacy Practice, Balaji Institute of Pharmaceutical Sciences, Narsampet, Warangal, for being abundantly helpful and offering invaluable assistance, support, and guidance. We express our special gratitude to Dr. G. Vijay Kumar, Dr. Raghunandan Neralla, and Dr. A. Rajendra Prasad Reddy and special thanks to patients and their caretakers for active participation in the study. All the figures (Figs. 2-14) are courtesy from PVK Sastry Children Hospital.

\section{AUTHORS' CONTRIBUTIONS}

Nandini Thummanapally, Kavitha Lawdyavath, and Charandas Guruva have contributed toward literature search, data collection, and manuscript writing; PVK Shastry contributed toward concepts and design of work; Deepthi Enumula contributed toward concept, design, manuscript editing, and data analysis; and Shyam Sunder Anchuri contributed toward manuscript editing.

\section{CONFLICTS OF INTEREST}

The authors declare that they have no conflicts of interest.

\section{AUTHORS' FUNDING}

Our study received no specific grant from any funding agency in the public, commercial, not for profit sector.

\section{REFERENCES}

1. Stamatas GN, Nikolovski J, Luedtke MA, Kollias N, Wiegand BC. Infant skin microstructure assessed in vivo differs from adult skin in organization and at the cellular level. Pediatr Dermatol 2010;27:125-31.

2. Stamatas GN, Nikolovski J, Mack MC, Kollias N. Infant skin physiology and development during the first years of life: A review of recent findings based on in vivo studies. Int J Cosmet Sci 2011;33:17-24.

3. Polat AK, Yesilova Y, Alatas ET, Belli AA, Dogan G, Picakciefe M. Prevalence of skin diseases of the pediatric population in the South
Eastern Anatolia, Turkey. Med Sci Monit 2018;7:664-7.

4. Saif GA, Al Shehab SA. Pattern of childhood dermatoses at teaching hospital of Saudi Arabia. Int J Health Sci 2008;2:63-74.

5. Rajashekar S, Kuruvila M, Bhat K, Bhaskaran U. Mucocutaneous manifestations following chemotherapy in pediatric malignancies. Asian J Pharm Clin Res 2016;9:161-4.

6. Shrestha R, Shrestha D, Dhakal AK, Shakya A, Shah SC, Shakya H. Spectrum of pediatric dermatoses in tertiary care center in Nepal. Nepal Med Coll J 2012;14:146-8.

7. Javed M. Neonatal dermatology at tertiary care teaching hospital. East J Med 2010;15:90-2.

8. Ali A. Prevalence of skin diseases in chak-36, union council, Ahmed Rajo, Taluka Shaheed Fazil, Rao (golarchi), district Badin, Sindh, Pakistan. Fuuast J Biol 2018;2:7-11.

9. Balakrishnan J, Appalasamy JR. Skin infection and the global challenges: A review. Int J Pharm Pharm Sci 2016;8:1-3.

10. Nnoruka EN. Skin diseases in South-East Nigeria: A current perspective. Int J Dermatol 2005;44:29-33.

11. Ogunbiyi AO, Daramola OO, Alese OO. Prevalence of skin diseases in Ibadan Nigeria. Int J Dermatol 2004:43:31-6.

12. Yahaya H. Change in patterns of skin disease in Kaduna North-central Nigeria. Int J Dermatol 2007;46:936-43.

13. Sardana K, Mahajan S, Sarkar R, Mendiratta V, Bhushan P, Koranne RV, et al. The spectrum of skin disease among Indian children. Pediatr Dermatol 2009;26:6-13.

14. Yasmeen N, Khan MR. Spectrum of common childhood skin diseases: A single centre experience. J Pak Med Assoc 2005;55:60-3.

15. Mostafa FF, Hassan AA, Soliman MI, Nassar A, Deabes RH. Prevalence of skin diseases among infants and children in Ai Sharqia governorate, Egypt. Dermatol Online J 2011;8:4.

16. Sethuraman G, Bhari N. Common skin problems in children. Indian J Pediatr 2014;81:381-90.

17. Dadapeer HJ, Anupama YG, Sushma DM, Aishwarya AC. Pattern of pediatric dermatoses at a tertiary care hospital, sims, Shivamogga. Indian J Clin Exp Dermatol 2018;4:201-4.

18. Karthikeyan K, Thappa DM, Jeevankumar B. Pattern of pediatric dermatoses in a referral center in South India. Indian Pediatr 2004;41:373-7.

19. Yeoh DK, Anderson A, Cleland G, Bowen AC. Are scabies and impetigo normalized? A cross sectional comparative study of hospitalised children in Northern Australia assessing clinical recognition and treatment of skin infection. PLoS Negl Trop Dis 2017;11:5726.

20. Kiprono SK, Muchunu JW, Masenga JE. Skin diseases in pediatric patients attending a tertiary dermatology hospital in Northern Tanzania: A cross-sectional study. BMC Dermatol 2015;15:16.

21. Essmat SM, Safoury O, El-Hanafy GM, Ahmed D, Rezk EM. Pattern of skin diseases among preschool and primary school-aged children in dermatology Damietta hospital. J Egypt Womens Dermatol Soc 2014; $11: 181-6$

22. Ogunbiyi AO, Owoaje E, Ndahi A. Prevalence of skin disorders in school children in Ibadan, Nigeria. Pediatr Dermatol 2005;22:6-10.

23. Kelbore AG, Owiti P, Reid AJ, Bogino EA, Wondewosen L, Dessu BK. Pattern of skin diseases in children attending a dermatology clinic in a referral hospital in Wolaita Sodo, Southern Ethiopia. BMC Dermatol 2019;19:5

24. Ravindra A, Shastry V, Prakash C, Betkerur J. A Study assessing the knowledge, attitude, and practices of parents regarding childhood hypopigmented lesions. Indian J Paediatr Dermatol 2019;20:122-7.

25. Fathi HI, Al-Samarai AG. Prevalence of Tinea capitis among school children in Iraq East Mediterr Health J 2000;6:128-37.

26. Ali-Shtayeh MS, Arda HM, Abu-Ghdeib SI. Epidemiological study of tinea capitis in school children in the Nablus area (West Bank). Mycoses 1998;41:243-8.

27. Akbas A, Kiline F, Yakut HI, Metin A. Superficial fungal infections in children. Med Sci Discov 2016;3:280-5.

28. Javed M, Jairamani C. Pediatric dermatology: An audit at Hamdard university hospital, Karachi. J Pak Assoc Dermatol 2006;16:93-6.

29. Hafi NB, Thokchom NS, Singh SC, Bachaspatimayum R. Childhood vitiligo: A hospital-based study on 200 patients in Northeast India. Indian J Paediat Dermatol 2019;20:128-33. 